\title{
Основы моделирования системы поддержки принятия решений по комплексному применению сил и средств ПВО надводных кораблей
}

\author{
H.A. Шустова ${ }^{1}$, к.m.н., старший научный сотрудник, komandor.99@mail.ru \\ B.B. Степанов 2, к.в.н., доиент, научный сотрудник, komandor.99@mail.ru
}

${ }^{1}$ НИИ "Центрпрограмисистем", г. Тверь, 170024, Россия

2 Военный институт (дополнительного профрессионального образования)

ВУНЦ ВМФ "Военно-морская академия", г. Санкт-Петербург, 195112, Россия

На основе теории боевых систем борьба с противником осуществляется в определенных физических средах или сферах вооруженной борьбы, с воздушно-космическим противником - в воздушно-космической сфере. В ВМФ Российской Федерации борьба с воздушным противником организована в противовоздушных контурах на различных уровнях управления.

В статье рассмотрены методологические основы разработки интеллектуальной системы поддержки принятия решений на комплексное применение сил и средств ПВО (истребительной авиации, зенитных огневых средств и средств радиоэлектронной борьбы) тактической группы надводных кораблей во взаимодействии с разнородными силами ПВО флота и других видов Вооруженных Сил РФ на театре военных действий.

Для разработки такой системы авторы предлагают организовать постоянно действующий комплексный имитационно-моделирующий стенд. Сведения о театре военных действий, характеристики противника и данные о комплексах ПВО должны стать исходной информацией для базы знаний комплексного имитационно-моделирующего стенда. На ее основе система управления базой знаний формирует модели решения задач для операторов расчетов ПВО надводных кораблей.

В выборе наиболее адекватной модели действий участвует эксперт-инфолог совместно с инженером по знаниям и должностными лицами расчетов командных пунктов ПВО. Информация, циркулирующая в комплексном имитационно-моделирующем стенде, формируется на основе извлеченного из достоверных источников опыта боевой подготовки, боевой службы, локальных войн и вооруженных конфликтов. В результате моделирования на таком стенде с использованием методов искусственного интеллекта появляется возможность создания «Динамической трехмерной модели борьбы с воздушным противником в боевом пространстве» с изменяющимся масштабом в режиме реального времени. Это позволит автоматизировать графики комплексного применения сил и средств ПВО надводных кораблей в составе тактических групп при обязательном внедрении в состав интегрированных систем боевого управления и тем самым повысить эффективность их боевого применения.

Ключевые слова: надводный корабль, тактическая группа, воздушно-космический противник, искусственный интеллект, противовоздушная оборона, воздушно-космическая оборона, база данных, база знаний, метод, модель, методика.

На современном этапе развития вооружения и военной техники надводные корабли ведут боевые действия в различных физических средах (сферах вооруженной борьбы). Для каждой физической среды надводный корабль имеет свой контур боевого управления борьбой с противником и использует соответствующее оружие. Контуры боевого управления борьбой с противником, находящимся в различных физических средах $[1,2]$, представлены в таблице.

Противовоздушный контур следует рассматривать как контур боевого управления силами и средствами ПВО, то есть путь, по которому функционируют командная информация и информация состояния (функционирования). Его целесообразно моделировать по взаимосвязанным функциональным подсистемам: освещения обстановки (разведки воздушного противника), поражения воздушного противника истребительной авиацией, зенитными огневыми средствами, подавления радиоэлектронных средств воздушного противника комплексами (станциями) активных помех, снижения эффективности ударов воздушного противника применением пассивных средств радиоэлектронной борьбы (РЭБ) и средств тактической маскировки, управления силами и средствами ПВО. 


\section{Контуры боевого управления борьбой с противником в зависимости от физической среды его нахождения}

The contours of the combat control of the fight against the enemy, depending on the physical environment of its location

\begin{tabular}{|l|l|l|}
\hline \multicolumn{1}{|c|}{$\begin{array}{c}\text { Физическая среда нахождения } \\
\text { противника }\end{array}$} & \multicolumn{1}{|c|}{$\begin{array}{c}\text { Оружие воздействия } \\
\text { на противника }\end{array}$} & \multicolumn{1}{c|}{ Боевой контур } \\
\hline Космическая & Противокосмическое & Противокосмический \\
\hline Воздушная & Противовоздушное & Противовоздушный \\
\hline Надводная и наземная (береговая) & Ударное & Ударный \\
\hline Подводная & Морское подводное & Противоподводный \\
\hline
\end{tabular}

Задачу борьбы с воздушно-космическим противником не решить отдельным, пусть и лучшим в мире суперкомплексом воздушнокосмической обороньл (ВКО). Согласно законам, закономерностям и принципам вооруженной борьбы на море повышение эффективности борьбы с воздушно-космическим противником возможно только на основе комплексного применения сил и средств ПВО (BKO) [3].

В условиях бурно развивающихся сил и средств вооруженной борьбы на море вопросы управления ими выходят на первый план. Весь научный мир активно работает в поисках наиболее эффективных систем управления боевыми системами будущего [4-6]. Одним из перспективных направлений является развитие интегрированных систем боевого управления (ИСБУ) на основе синергетического подхода, то есть объединения для реализации боевых возможностей сил и средств вооруженной борьбы различных видов Вооруженных Сил РФ и других ведомств.

Схема уровней управления силами и средствами борьбы с воздушно-космическим противником на театре военных действий показана на рисунке 1 .

На первом уровне управления находится начальник Национального центра управления обороной. Это Центральный командный пункт Генерального штаба Вооруженных Сил РФ.

На втором уровне управления находится командующий объединенным стратегическим командованием на театре военных действий. Он командует межвидовой группировкой сил, для борьбы с воздушно-космическим противником развертывается пункт управления (ПУ) ВКО.

На третьем уровне управления под руководством командира группировки разнородных сил развертывается ПУ ПВО.

На четвертом уровне управления под руководством командира тактической группь (ТГ) ПУ ПВО возглавляет начальник ПВО ТГ.
На пятом уровне управления в составе ПУ ПВО ТГ функционируют следующие ПУ:

- пост освещения воздушной обстановки, входящий в состав ПУ освещением обстановки под руководством флагманского специалиста радиотехнической службы, который, кроме освещения воздушной обстановки, отвечает за освещение надводной и подводной обстановки;

- ПУ зенитными огневыми средствами под руководством флагманского специалиста ракетно-артиллерийского оружия;

- ПУ разведкой под руководством начальника разведки;

- ПУ РЭБ под руководством флагманского специалиста РЭБ;

- ПУ истребительной авиацией.

На шестом уровне управления под руководством командира надводного корабля его старший помощник возглавляет командный пункт (КП) ПВО. Он же является начальником ПВО надводного корабля.

На седьмом уровне управления средствами ПВО в составе КП ПВО надводного корабля функционируют следующие КП:

- пост освещения воздушной обстановки в составе КП освещения обстановки (в том числе надводной и подводной), который возглавляет командир радиотехнической боевой части;

- КП управления зенитными огневыми средствами, который возглавляет командир ракетно-артиллерийской боевой части;

- КП разведки и РЭБ, который возглавляет командир группы разведки и РЭБ;

- КП управления истребительной авиацией, который возглавляет офицер боевого управления в зависимости от принятой на флоте организации.

На восьмом уровне управления функционируют командиры комплексов ПВО (зенитных огневых, комплексов РЭБ и др.).

В дальнейших научных исследованиях целесообразно решать проблему повышения опе- 


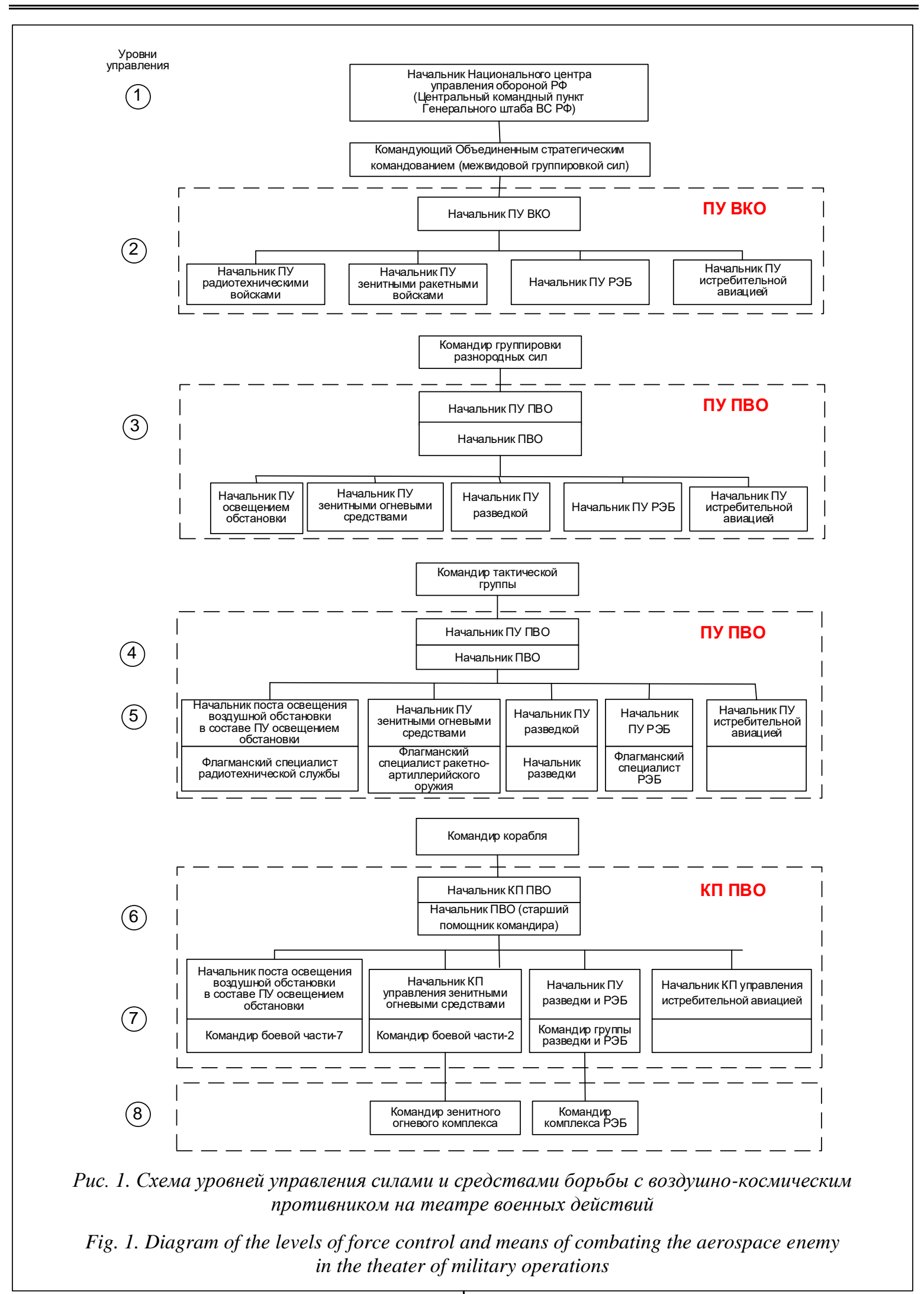

ративности управления силами и средствами борьбы с воздушно-космическим противником за счет автоматизации процесса управления и сокращения количества уровней управления. В идеале нужно стремиться к реализации в системах управления режима реального времени. 
В связи с тем, что возможности человека (командира корабля или ТГ) обработать большие объемы оперативной информации при управлении сложными организационно-техническими системами ограничены, возникла необходимость в развитии специальных систем, призванных помогать лицу, принимающему решения, более объективно оценивать сложившуюся обстановку и на основании оценки предлагать наилучшие варианты действий. Это положило начало бурному развитию систем поддержки принятия решений, которые объединяют научно обоснованные и проверенные практикой знания и возможности информационных технологий, организуя процесс получения, представления и обработки информации [7-9].

Системы поддержки принятия решений являются человеко-машинными, позволяющими лицу, принимающему решения, использовать данные, знания, объективные и субъективные модели для анализа и решения слабоструктурированных проблем.

В эти системы объединяются на общей основе методы, характерные для следующих направлений исследований:

- принятие решений;

- извлечение и представление знаний;

- построение диалоговых систем.

До недавнего времени для решения конкретных задач управления, требующих всестороннего учета всех процессов и явлений, привлекался формальный математический аппарат, гарантирующий строгое и точное обоснование получаемых выводов и рекомендаций. Такой аппарат базировался преимущественно на количественных (числовых) методах математического моделирования и оптимизации, однако при использовании только количественных методов зачастую происходит потеря важных аспектов, не поддающихся формализации. В то же время качественное рассмотрение, основанное на полном (пусть интуитивном) учете взаимосвязанных факторов, подчас имеет более важную практическую значимость.

Очевидно, что построить строгую количественную модель объекта исследования чрезвычайно трудно и решение задачи приходится искать в классе других методов. К числу таких методов, получивших развитие в последние годы и ориентированных на изучение объектов и процессов с указанными свойствами, относятся методы логико-лингвистического моделирования. Они входят в один из разделов теории искусственного интеллекта, который базируется на воспроизведении (имитации) таких механизмов мышления человека, как восприятие и накопление знаний, структурирование и оценка ситуации, целеобразование и планирование поведения, а также на использовании для этих целей искусственных языков, близких по своим свойствам к естественным.

В логико-лингвистическом моделировании широко используются достижения таких общенаучных дисциплин, как математическая логика, психология, математическая лингвистика, информационные технологии. Оно занимает некоторое промежуточное положение между строго формальными моделями количественной оценки и качественно-эвристическими подходами. Методы логико-лингвистического моделирования не подменяют строго количественных методов моделирования и оптимизации, а способствуют более обоснованному выявлению таких ситуаций, когда обеспечивается более эффективное количественное решение задач, однако при этом не теряется содержательная трактовка результатов.

Для моделирования кибернетических систем предлагался не очередной математический монстр, понятный лишь автору и его ближайшему окружению, а набор вполне прозрачных нотаций для описания объектов системы управления и связей между ними [5]. Впервые отчетливо прозвучала мысль, что существуют задачи, где строгая математика бессильна, но логика, обогащенная лингвистическими моделями, может дать результативное и ясное описание [10-13].

Предлагаем использовать логико-лингвистическое моделирование для разработки интеллектуальной системь информационной поддержки принятия решений (ИСИППР) на комплексное применение сил и средств борьбы с воздушно-космическим противником.

Вариант построения комплексного имитационно-моделирующего стенда исследования функционирования противовоздушных контуров надводных кораблей и ТГ показан на рисунке 2.

Исходной информацией (сведениями) для этой системы являются параметры внешней среды, противника и комплексов ПВО. СУБД преобразует их в данные, которые, в свою очередь, являются исходной информацией для БЗ.

Знания позволяют интеллектуальной системе формировать рекомендации пользова- 
телю для принятия решений относительно возникающих перед ним конкретных задач.

СУБЗ включает в себя решатель-интерпретатор - программу, моделирующую ход решения задачи на основании знаний, имеющихся в Б3. Интерпретатор с помощью специальных процедур находит в этой базе методы для формирования модели, адекватной тактической ситуации. На основе модели формируется методика решения задачи, формирующая интеллектуальный интерфейс на автоматизированном рабочем месте (АРМ) должностного лица ИСБУ.

Одной из частей СУБЗ является подсистема объяснений - программа, позволяющая оператору АРМ управления комплексами ПВО найти ответы на вопросы о том, как была получена та или иная рекомендация и почему ИСИППР приняла такое решение. Ответ на вопрос «как?»- это трассировка всего процесса получения решения с указанием использованных фрагментов Б3, то есть всех шагов цепи умозаключений. Ответ на вопрос «почему?»ссылка на умозаключение, непосредственно предшествовавшее полученному решению, то есть отход на один шаг назад.

Коротко остановимся на построении экспертной системы (рис. 2).
В рассматриваемом методологическом подходе экспертная система - это не только классический опрос экспертов вживую, а работа с их трудами (АРМ экспертов). При этом при моделировании процесса борьбы с воздушнокосмическим противником ведущий инфологэксперт и инженер по знаниям обращаются к различным источникам, содержащим знания экспертов (учебники, учебные пособия, монографии, статьи и т.д.), и используют такую информацию с обязательными ссылками на источники в соответствии с принципами научной этики.

Системообразующим лицом в таком проекте является ведущий инфолог-эксперт, работающий в тесном сотрудничестве с инженером по знаниям, экспертами и практиками флота, то есть с должностными лицами расчетов (КП ПВО) надводных кораблей и ПУ ПВО ТГ [4].

Инженер по знаниям - это координатор работы с двумя системами. Он работает с СУБД и СУБЗ. Здесь как раз и кроется ядро исследований, которое реализует добывание знаний и управление ими с помощью самых передовых интеллектуальных технологий.

Работа в диалоговом режиме с ИСИППР ведущего инфолога-эксперта в рамках постоянно

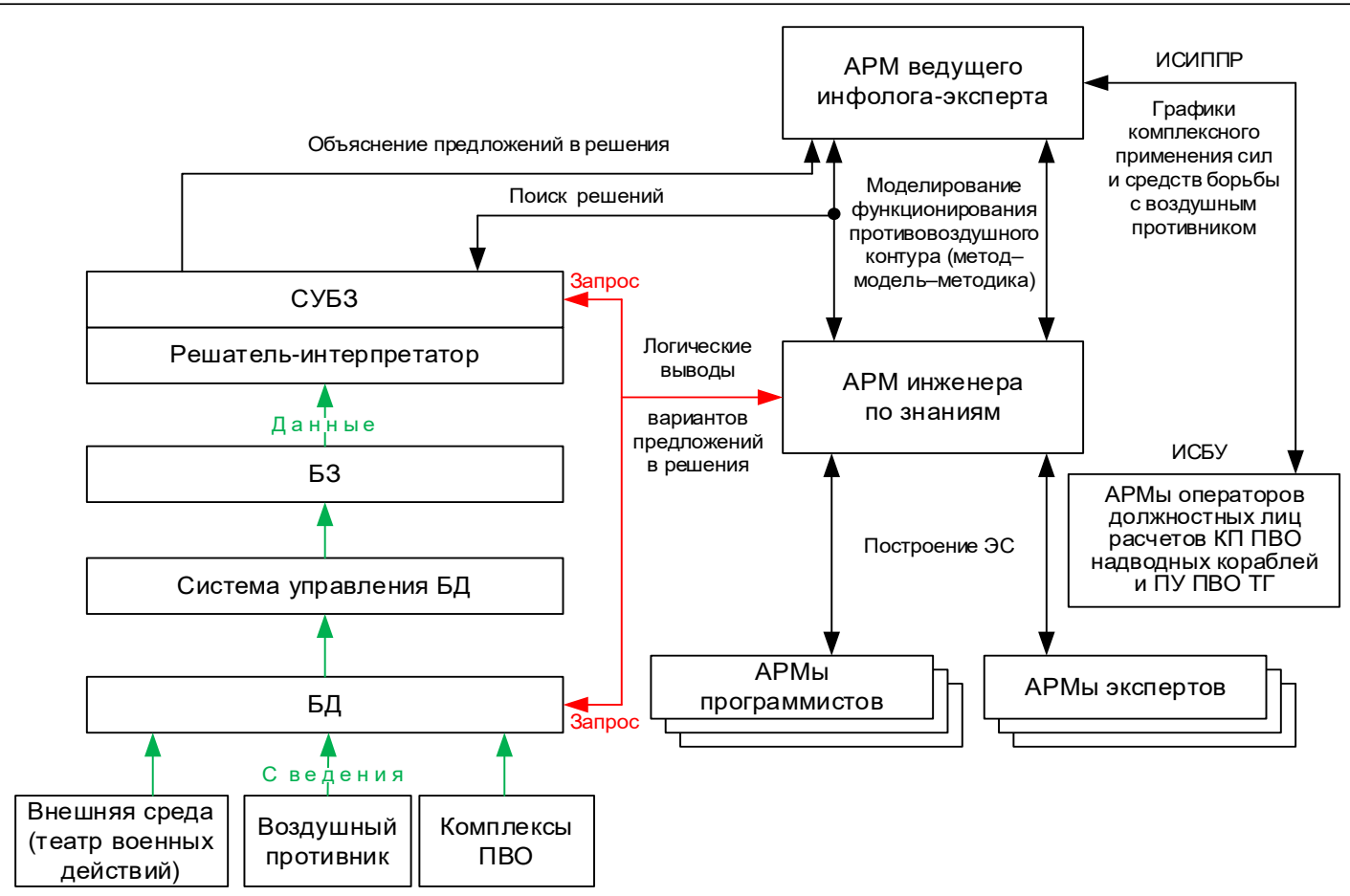

Рис. 2. Схема комплексного имитационно-моделирующего стенда исследования функиионирования противовоздушных контуров надводных кораблей и ТГ

Fig. 2. The scheme of the complex simulation and simulation stand for the study of the functioning of the anti-aircraft contours of surface ships and TG 
действующего проекта призвана способствовать решению практических задач в интересах флота.

Предполагается, что функционирование такого стенда должно осуществляться круглосуточно без выходных даже при отсутствии операторов за АРМ. Реализация данного проекта научных исследований при использовании такого стенда имеет колоссальное значение для решения задач борьбы с воздушно-космическим противником на всех уровнях управления. Поэтому здесь излагается идея организации таких исследований, которая в процессе развития может меняться, то есть быть адаптивной применительно к меняющейся ситуации.

Разработка такой ИСИППР должна сопровождаться исследованиями, направленными на внедрение ее в ИСБУ надводных кораблей на всех уровнях управления.

Актуальность функционирования такого стенда возрастает для оказания оперативной поддержки принятия решений командирам надводных кораблей, находящимся на боевой службе. Использование тренажерных комплексов и предлагаемого стенда позволит организовать подготовку боевых расчетов к будущим, а не ко вчерашним боевым действиям [14].

В настоящее время на надводных кораблях флотов используются графики комплексного применения неавтоматизированных средств ПВО, которые применяются только при планировании боевых действий и имеют ограниченный характер использования. Применение таких графиков теряет смысл, если их не автоматизировать и не внедрить в ИСБУ. Сделать это можно на основе моделирования ИСИППР.

График комплексного применения сил и средств борьбы с воздушным противником на основе ИСИППР на театре военных действий должен содержать программу «Интеллектуальный помощник командира», в которой заложены режимы «Советник» и «Автомат». Тогда лицо, принимающее решение в случаях, когда время позволяет подумать и принять свое решение (например, если дистанция до противника Д $\geq 500$ км), установит режим «Советник». Если же воздушный противник активно применяет средства поражения (Д $\leq 50-30$ км) к кораблям ТГ, целесообразнее перейти в режим «Автомат» и не полагаться на человеческий фактор.

На графике может быть показано комплексное применение истребительной авиации, зенитных ракетных войск, береговых частей РЭБ
Воздушно-космических сил с участием сил и средств ПВО кораблей ВМФ. Управление межвидовой группировкой сил и средств ПВО (ВКО) на театре военных действий осуществляется с ПУ ВКО, то есть со второго уровня управления (рис. 1).

Предлагается на графике отображать прогнозируемые действия воздушного противника и планируемые действия сил и средств ПВО ТГ кораблей во взаимодействии с силами ПВО воздушно-космических сил. Планируемые действия сопровождаются расчетами эффективности, предлагаемыми вариантами решений и их объяснением (рис. 2). В базе знаний постоянно накапливаются и корректируются варианты решений, что позволяет анализировать их и выбирать наилучшие применительно к той или иной тактической ситуации. Фактическая обстановка должна отображаться на АРМ ИСБУ в том же масштабе и режиме реального времени.

В случае внедрения ИСИППР в ИСБУ данные о воздушном противнике и наших силах автоматически поступают и отображаются на экране АРМ ИСБУ. Оператор АРМ ИСБУ контролирует правильность и отождествляет поступающую информацию из различных источников. Он имеет возможность корректировать отображение информации и вести диалог с ИСИППР с помощью интеллектуального интерфейса, анализировать предложения в решение в режиме «Советник». Далее начальник ПУ ПВО ТГ в зависимости от развития противовоздушного боя принимает решение о переходе в режим «Автомат». В этом случае операторы не вмешиваются в функционирование системы ИСИППР-ИСБУ, а только контролируют процесс автоматического управления силами и средствами ПВО ТГ.

График отображает процесс противовоздушного боя в вертикальной плоскости, но этого недостаточно и необходимо предусмотреть возможность отображения обстановки в горизонтальной плоскости и в трехмерном пространстве. При разработке ИСИППР может быть реализована «Динамическая трехмерная модель борьбы с воздушным противником в боевом пространстве» с изменяющимся масштабом в режиме реального времени.

Заслуживает пристального внимания и изучения опыт иностранных ВМС по внедрению интеллектуальных систем управления.

Техническую основу корабельной системы ПВО ВМС США и НАТО составляют многофункциональная система управления ору- 
жием корабля «Иджис», корабельные боевые информационно-управляющие системы семейства NTDS, ACУ оперативным соединением и распределением данных ПВО/ПРО соединения (Cooperative Engagement Capability - CEC) и быстродействующие системы связи и обмена данными Линк-11, Линк-16.

Автоматическое целераспределение (назначение для поражения каждой цели конкретного корабельного зенитного ракетного комплекса) в масштабах корабельной группы обеспечивает сокращение времени реакции на возникновение воздушной угрозы. В системе СЕС заложен простой принцип целераспределения, предусматривающий перехват заданной воздушной цели первым назначенным для этого кораблем или выбор наиболее оптимального средства поражения каждой воздушной цели с учетом конкретных условий изменяющейся обстановки морского боя.

При организации перехвата воздушной цели по внешним данным (от взаимодействующего корабля) аппаратура СEC в качестве источника внешних данных, используемых при наведении зенитной управляемой ракеты, выбирает ту радиолокационную станцию, которая в данной ситуации выдает наиболее качественные данные по цели. Эта задача решается автоматически исходя из состава и тактического ордера своей корабельной группы (типов корабельных радиолокационных станций) после оценки тактической и радиоэлектронной обстановки.

Возможность дистанционного управления пуском с последующим наведением зенитной управляемой ракеты из боезапаса, взаимодействующего в системе СЕС корабля, обеспечивает большую гибкость применения средств ПВО/ПРО оперативного соединения.

Таким образом, АСУ СЕС обеспечивает новые варианты организации и проведения перехвата воздушных целей, включая автоматическое целеуказание от внешнего источника, пе- рехват по внешним данным, дистанционное управление пуском с последующим наведением зенитной управляемой ракеты из боезапаса взаимодействующего корабля, последовательное наведение одной ракеты двумя кораблями.

Вооружение кораблей ВМС стран НАТО современными зенитными ракетными комплексами и АСУ оперативного соединения СЕС позволяет создать пространственно-распределенную мобильную систему зональнообъектовой ПВО, способную к гибкому наращиванию исходя из конкретных условий обстановки. Оперативный обмен информацией между элементами данной системы значительно повышает ее возможности, особенно в борьбе с малоразмерными и малозаметными целями. На всех надводных кораблях ВМС США и НАТО, имеющих на вооружении боевые информационно-управляющие системы «Иджис», внедрена система «Сервис распределения данных» - DDS (Data Distribution Service) [15].

Таким образом, в настоящее время во всем мире происходит бурное развитие интеллектуальных систем управления, основанных (в том числе) на методах искусственного интеллекта. Методология научных исследований в этом вопросе предполагает отталкиваться от предметной области и проблем, которые выдвигает практика флота. В данном случае - это проблема комплексного применения сил и средств ПВО надводных кораблей, решающих боевые задачи в составе ТГ. Одним из путей решения этой проблемы является разработка ИСИППР на комплексное применение сил и средств ПВО надводных кораблей ВМФ с использованием методов искусственного интеллекта. Для разработки такой системы целесообразно создать комплексный имитационно-моделирующий стенд для выработки и обоснования предложений по организации подготовки к будущим боевым действиям на море.

\section{Лumepamypa}

1. Третьяков О.В., Нефедович А.В., Степанов В.В., Голубев А.В. Эргономическая парадигма создания боевых контуров надводного корабля // Морская радиоэлектроника. 2018. № 3. С. 2-7.

2. Третьяков О.В., Нефедович А.В., Степанов В.В., Голубев А.В. Методические основы эргономического обеспечения разработки боевых контуров тактической группы надводных кораблей // Морская радиоэлектроника. 2019. № 3. С. 6-11.

3. Грудинин И.В., Майбуров Д.Г. Содержание и структура категории «Информационно-управленческий ресурс отражения удара средств воздушно-космического нападения противника» // Вестн. АВН. 2018. № 1. С. 104-111. 
4. Коротков Э.М. Исследование систем управления. М.: ИНФРА-М, 2003. 176 с.

5. Соловьев И.В., Геков В.В., Доценко С.М. Современные проблемы управления силами ВМФ. Теория и практика. Состояние и перспективы. СПб: Политехника, 2006. 288 с.

6. Шпак В.Ф., Директоров Н.Ф., Мирошников В.И., Наумов В.Н., Серегин А.В., Синещук Ю.И., Туровский О.М. Информационные технологии в системе управления силами ВМФ (теория, практика, состояние и перспективы развития). М.: Элмор, 2005. $832 \mathrm{c}$.

7. Довженко В.Н., Завгородний В.Н. Поддержка принятия решений при управлении войсками (силами) // Военная мысль. 2014. № 6. С. 19-25.

8. Титков И.В. Система информационно-интеллектуальной поддержки принятия решений при управлении средствами и комплексами радиоэлектронной борьбы ВМФ // Морской сборник. 2014. № 9. C. 35-41.

9. Ягольников Д.В., Допира Р.В., Шведун А.А. Интеллектуальная система информационной поддержки принятия решений при управлении технической эксплуатацией систем вооружения радиотехнических войск // Военная мысль. 2019. № 3. С. 13-19.

10. Поспелов Д.А. Логико-лингвистические модели в системах управления. М.: Энергоиздат, 1981 $232 \mathrm{c}$.

11. Степанов В.В. Методологические основы разработки интеллектуальной системы информационной поддержки принятия решений при управлении зенитными огневыми средствами надводных кораблей // Актуальные проблемы защиты и безопасности: тр. XXIII Всерос. науч.-практич. конф. РАРАН. T. 3. C. $28-33$.

12. Гаврилова Т.А., Хорошевский В.Ф. Базы знаний интеллектуальных систем. СПб: Питер, 2000. $383 \mathrm{c}$.

13. Геловани В.А., Башлыков А.А., Бритков В.Б., Вязилов Е.Д. Интеллектуальные системы поддержки принятия решений в нештатных ситуациях с использованием информации о состоянии природной среды. М.: Эдиториал УРСС, 2001. 304 с.

14. Ильин В.А., Соколов С.Н., Пахомов Е.С., Шуванов А.Д. Тактические тренажерные комплексы для подготовки к ведению боевых действий на море // Программные продукты и системы. 2016. № 1 . C. 22-30. DOI: 10.15827/0236-235X.113.022-026.

15. Оркин Б.Д., Оркин С.Д. Имитационное моделирование боевого функционирования палубных истребителей, зенитных ракетных и артиллерийских групп при решении задач ПВО. М.: Изд-во МАИ, 2009. $700 \mathrm{c}$.

\title{
Fundamentals of modeling a decision support system for the integrated use of surface ship air defense forces and assets
}

\author{
N.A. Shustova ${ }^{1}$, Ph.D. (Engineering), Senior Researcher, komandor.99@mail.ru \\ V.V.Stepanov ${ }^{2}$, Ph.D. (Military Sciences), Associate Professor, Research Associate, komandor.99@mail.ru \\ ${ }^{1}$ R\&D Institute Centerprogramsystem, Tver, 170024, Russian Federation \\ ${ }^{2}$ Military Institute of Continuing Professional Education of the VUNTS Navy "Naval Academy", \\ St. Petersburg, 195112, Russian Federation
}

Abstract. Based on the combat system theory, the fight against the enemy is carried out in certain physical environments or areas of armed struggle, with the aerospace enemy in the aerospace sphere. In the Navy of the Russian Federation, the fight against the air enemy is organized in anti-aircraft circuits at various levels of control. 
The paper considers the methodological basis for the development of an intelligent decision support system for the integrated use of air defense forces and means (fighter aircraft, anti-aircraft fire, and electronic warfare) of a tactical group of surface ships in interaction with heterogeneous air defense forces of the fleet and other types of the Armed Forces of the Russian Federation in the theater of military operations.

To develop such a system, the authors propose to organize a permanent complex simulation and modeling stand.

Information about the theater of military operations, enemy characteristics, and data on air defense systems should be the source information for the knowledge base of the complex simulation and modeling stand. On its basis, the knowledge base management system forms problem-solving models for operators of surface ship air defense calculations.

In choosing the most appropriate model of action, an expert-infolog with a knowledge engineer and officials of the calculations of air defense command posts.

We formed the information circulating in the complex simulation and modeling stand based on the experience of combat training, combat service, local wars, and armed conflicts extracted from reliable sources.

Because of modeling on such a stand using artificial intelligence methods, it becomes possible to create a "Dynamic three-dimensional model of the fight against an aerial enemy in combat space" with a changing scale in actual time.

This will make it possible to automate the schedules of the integrated use of surface ships' air defense forces and means as part of tactical groups, with the mandatory introduction of integrated combat control systems, and increase the effectiveness of their combat use.

Keywords: surface ship, tactical group, aerospace enemy, artificial intelligence, air defense, aerospace defense, database, knowledge base, method, model, methodology.

\section{References}

1. Tretyakov O.V., Nefedovich A.V., Stepanov V.V., Golubev A.V. Ergonomic paradigm for creating of combat contours of a surface ship. Marine Radio Electronics, 2018, no. 3, pp. 2-7 (in Russ.).

2. Tretyakov O.V., Nefedovich A.V., Stepanov V.V., Golubev A.V. Methodological foundations of ergonomic support for development of combat contours of surface ship tactical group. Marine Radio Electronics, 2019, no. 3, pp. 6-11 (in Russ.).

3. Grudinin I.V., Mayburov D.G. Content and structure of category "Information and management resources reflections of impact of aerospace attack means". Vestn. AVN, 2018, no. 1, pp. 104-111 (in Russ.).

4. Korotkov E.M. Research of Control Systems. Moscow, 2003, 176 p. (in Russ.).

5. Solovev I.V., Gekov V.V., Docenko S.M. Modern Problems of Managing the Forces of the Navy: Theory and Practice. Status and Prospects. St. Petersburg, 2006, 288 p. (in Russ.).

6. Shpak V.F., Direktorov N.F., Miroshnikov V.I., Naumov V.N., Seregin A.V., Sineshchuk Yu.I., Turovsky O.M. Information Technologies in the Naval Forces Management System (Theory, Practice, State and Prospects of Development). Moscow, 2005, 832 p. (in Russ.).

7. Dovzhenko V.N., Zavgorodny V.N. Support for decision-making within control of troops (forces). Military Thought, 2014, no. 6, pp. 19-25 (in Russ.).

8. Titkov I.V. The system of information and intellectual support for decision-making in the management of the Navy electronic warfare means and complexes. Naval Digest, 2014, pp. 36-41 (in Russ.).

9. Yagolnikov D.V., Dopira R.V., Shvedun A.A. The intelligence system of information support of decision making in managing technological operation of armament systems for the radio-engineering troops. Military Thought, 2019, no. 3, pp. 13-19 (in Russ.).

10. Pospelov D.A. Logical-linguistic Models in Control Systems. Moscow, 1981, 232 p. (in Russ.).

11. Stepanov V.V. Methodological foundations for developing an intelligent information support system for decision-making in controlling anti-aircraft fire weapons of surface ships. Proc. 23th All-Russ. Sci.-Pract. Conf. Relevant Protection and Security Problems, vol. 3, pp. 28-33 (in Russ.).

12. Gavrilova T.A., Khoroshevsky V.F. Knowledge Bases of Intelligent Systems. St. Petersburg, 2000, 383 p. (in Russ.). 
13. Gelovani V.A., Bashlykov A.A., Britkov V.B., Vyazilov E.D. Intelligent Decision Support Systems in Emergency Situations Using Information About the State of the Natural Environment. Moscow, 2001, 304 p.

14. Ilin V.A., Sokolov S.N., Pakhomov E.S., Shuvanov A.D. Tactical simulator complexes for naval combat training. Software and Systems, 2016, no. 1, pp. 22-30. DOI: 10.15827/0236-235X.113.022-026 (in Russ.).

15. Orkin B.D., Orkin S.D. Simulation Modeling of the Combat Functioning of Carrier-Based Fighters, Anti-Aircraft Missile and Artillery Groups When Solving Air Defense Tasks. Moscow, 2009, 700 p. (in Russ.).

\section{Для цитирования}

Шустова Н.А., Степанов В.В. Основы модемирования системы поддержки принятия решений по комплексному применению сил и средств ПВО надводных кораблей // Программные продукты и системы. 2021. Т. 34. № 2. С. 344-353. DOI: 10.15827/0236-235X.134.344-353.

\section{For citation}

Shustova N.A., Stepanov V.V. Fundamentals of modeling a decision support system for the integrated use of surface ship air defense forces and assets. Software \& Systems, 2021, vol. 34, no. 2, pp. 344-353 (in Russ.). DOI: 10.15827/0236-235X.134.344-353. 